\title{
Comparing the incomparable: Trust in media and state institutions
}

\author{
Gintaras Aleknonis ${ }^{1}$ \\ Mykolas Romeris University, Vilnius, Lithuania
}

\section{doi:10.5937/comman1326125A}

Summary: Expressions of public trust in media and state institutions are contradictive; their comparison should be evaluated with certain reservations. In order to compare trust in media and state institutions throughout Europe, a very simple Comparative Media Trust Index (CMTI) was designed. The CMTI is based on comparison of trust in five state institutions and three media types, and was used for a pilot analysis to compare trust in media and state institutions throughout Europe. For this analysis, the level of 'gross trust' (which was calculated by summing up trust in media and the three most trusted state institutions) was taken into account. The research helped identify four models of trust (Transitional, Nordic, Post-communist and Mediterranean) which were compared with three media systems proposed by Daniel Hallin and Paolo Mancini. The first insights gained through the CMTI regarding the balance between trust in media and state institutions throughout Europe could lead to rather optimistic conclusions. In experienced democracies, primary trust is placed in democratically elected state institutions, and trust in media could be characterised as secondary. Countries with fresh reminiscences of a totalitarian past still live in a transitional period where the understanding of the roles of the state and the media is influenced by negative memories of distrust in elected bodies.

Keywords: trust, media, media system, state institution

\section{Introduction}

Trust, "the foundation of the social relationship that we call citizenship" (Coleman, 2012: 36), in one or another form is important to nearly all social scientists. This broad field of research is one of the significant meeting points

\footnotetext{
1 gintaras@gmail.com
} 
for political theory, philosophy, ethics, sociology, communication and media studies. "The silent presence [of trust] can be detected in all main sociological writings" (Misztal, 1996: 1). This happens throughout the history of human thought; high interest in this topic is expressed in a range of significant texts, starting with classical works by Aristotle to promises of 'the end of history' by Francis Fukuyama, and even further.

Despite such great interest on behalf of scholars, we should acknowledge the absence of a complete and widely accepted description of trust, not to mention attempts to present qualitative or quantitative explanations of this phenomenon. Diverse efforts to describe such specific varieties of trust, such as trust in media or trust in state institutions, are only a few of a number of examples confirming the complexity of the problem. "Scholars seem to agree that we still lack a theoretically derived, reliable and validated instrument for the measurement of trust in news media" (Kohring \& Matthes, 2007: 232). A superficial glance at the research field indirectly confirms that trust could be characterised as a relatively subjective category, and from many points of view is an immeasurable phenomenon.

The principal objectives of this article are:

1. to explain the possible contradiction between trust in media and state institutions, which lays the theoretical foundation for our comparison; ${ }^{2}$

2. to propose an instrument for the comparison of trust in media and state institutions;

3. with the help of this instrument, to compare trust in media and state institutions throughout Europe;

4. on the basis of this comparison, to propose different models of trust and look for their links with well-known media systems described by Daniel Hallin and Paolo Mancini (2004).

\section{Incomparable factors}

Trust exists in diverse forms and on different levels. It is complicated to evaluate or compare a child's sincere trust in their parents with the critical (dis) trust of an armchair economist in the articles of a daily newspaper predicting bright economic prospects in the middle of a crisis.

\footnotetext{
The more deep and comprehensive theoretical context of the problem of trust is provided in the editorial introduction as well as in other articles of this volume.
} 
In this volume, all of the authors are dealing with a particular and very specific sort of trust, i.e. communication trust. Without fear of overestimating the importance of communication in human life, we must remember that communication cannot exist without a certain degree of trust. These are inseparable categories. Even if somebody is under the influence of disinformation and understands the oddness of such a situation, they must trust that received messages are provided by an unreliable source. As Niklas Luhmann precisely notes, "[d]istrust, however, is not just the opposite of trust; as such, it is also a functional equivalent for trust" (Luhmann, 1979: 71). This observation is particularly relevant in the context of communication and highlights the conditional nature of trust. The fact is often overlooked in the routine analysis of surveys on trust or distrust.

Trust and truth, distrust and lies nearly always have moral, evaluative aspects. The functional understanding of trust should help us to take a more or less neutral look at the problem. We presume that communicative relationships between citizens and state or citizens and media should be based on trust, which in turn serves as a fundament of social relationship. Together with Fukuyama, we were able to trace three broad paths to sociability:

"[T] he first is based on family and kinship, the second on voluntary organisation outside of kinship such as schools, clubs and professional organisations, and the third is the state. [...] The first and third paths, it turns out, are closely related to one another: cultures in which the primary avenue toward sociability is family and kinship have a great deal of trouble creating large, durable economic organisations, and therefore look to the state to initiate and support them" (Fukuyama, 1996: 62-63).

As Adam Seligman observes, "Fukuyama presents what are really two, not three, models, one based on the familiarity of kinship and one which encompasses that element of trust which is an aspect of voluntary associations" (Seligman, 1997: 91).

It is difficult to resist the temptation to extend these ideas and base our further research on the duality of trust in state and media. The model of trust in family and state could be characterised as more or less stable; in most communities this model is inherited, passed from one generation to another and supported by formal procedures or rituals. Such conditional stability of institutional trust could be linked with certain civic expectations and visions of social protection. On the other hand, we would like to present trust in voluntary associations as some sort of changeable phenomenon, which could be 
associated with the choice to trust one or another channel of information. To some degree, it could be defined as market-based trust. The direct transfer of such a dual model of trust into media and communication studies could entail definite risks. First of all, certain doubts persist about the influence of voluntary associations on the overall level of trust. As Kenneth Newton notes: "voluntary associations do not seem to matter" (Newton, 2007: 356). The second point could be summarised as a question: does trust in media really coincide with the 'second path of trust' and is it comparable with trust in voluntary associations? From our point of view, the first doubt remains an open question, as neither side has persuasive evidence to support their contradictive attitudes. As regards the second point, we would like to stress the voluntary use and selection of media channels. We should pay special attention to new communication technologies (which personalise the media and open new and less formal channels) and at the same time to the rise of unofficial networks for the dissemination of information (which substitute old media), as it helps to validate parallels between media and voluntary associations.

Our presumption is that the more society and its members understand the difference between trust in media and state institutions, the more they are inclined to trust democratically elected bodies. It is natural for societies to foster an illusion about the essential differences between the egoistic purposes of the media and state institutions, and on these grounds, to try to oppose them. Media empires make enormous efforts to mask their business interests and present themselves as consistent defenders of an ordinary folk, or in the worst case, as innocent entertainers. Most state institutions face a difficult choice between elitist secrecy and populist propaganda.

Expressions of public trust in media and state institutions are contradictive; their comparison should be evaluated with certain reservations, but nevertheless is worth exploring. We can foster expectations that the comparison of trust in media and state institutions can expose certain peculiarities of different societies, and reveal strengths and weaknesses of their democratic foundations and models of media functioning.

\section{Comparative media trust index}

In order to compare trust in media and state institutions throughout Europe, we designed a very simple Comparative Media Trust Index (CMTI) based on real (or imaginable) contradiction between trust in state institutions and in media. 
In the very beginning, we had to overcome basic obstacles and answer the question: what institutions represent the modern state in the mind of contemporary Europeans? Our choice of indicators was partly limited by the accessible data used for the measurement of trust by different waves of the Standard Eurobarometer. In our case, the available options were limited to indicators of trust in (1) justice/national legal system; (2) the police; (3) the army; (4) religious institutions; (5) trade unions; (6) big companies; (7) political parties, (8) the national government; (9) the national parliament; and (10) small companies. With some reservations, five indicators ${ }^{3}$ were chosen for comparison with trust in different types of media. Such a choice is based primarily on data availability, but, on the other hand, the composition of these five indicators in particular is rather balanced. Two of the indicators (the national government and the national parliament) may depend on sudden changes in the mood of the population, short-term success or sudden downfalls of administration. The other two indicators (justice/national legal system and the police) represent more stable attitudes which theoretically are independent from political and administrative spheres and should be less associated with unexpected changes in mood. The fifth indicator (the army) may look a bit outdated, but for recently reborn states, trust in the army may have a rather symbolic value.

As regards the media, we relied on data about three 'classical types' of trust: the press, radio and television. Data about trust in the internet was not incorporated into CMTI calculations because of the assumption that the understanding of 'trust in the internet' for the time being could be too wide-ranging and controversial as it could include not only trust in media web pages, but also trust in social media or commercial websites. The other reason for the exclusion of 'trust in the internet' was the existence of official web pages provided by state institutions. The boundaries between different types of media on the internet are not fixed in the mind of survey participants, and the inclusion of 'trust in the internet' into the CMTI for the time being would only add unnecessary confusion.

Taking into account the abovementioned problems, the CMTI was based on the comparison of trust in five state institutions and three media types. The first step was to calculate the difference between those who 'tend to trust' and 'tend not to trust', and who receive a (positive or negative) 'score of trust' in five state institutions and three media types in all surveyed European coun-

3 (1) justice/national legal system; (2) the police; (3) the army; (8) the national government; and (9) the national parliament. Unfortunately, data about trust in regional/local public authorities are not available in all editions of the Standard Eurobarometer. 
tries. Then, three of the most trusted state institutions in every country ${ }^{4}$ were compared with three media types and arranged in a line according to popular trust. For example, the 'formula' SSMMSM means that, according to overall European data in 2010, two state institutions were trusted most, followed by two media types, a state institution and the third media type (the army was the most trusted institution $(+49)$, followed by the police $(+32)$, radio $(+22)$, television $(+5)$, justice/national legal system $(-1)$ and the press $(-10))$. In order to translate such a formula into a more comparable form, we counted 'trust points', giving 60 points for the first (most trusted) position, 50 points for the second, etc. So the all-European model formula SSMMSM was 'translated' into 130 'trust points' for state institutions ( 60 points for army, 50 for police and 20 for justice/national legal system) and 80 'trust points' for the media (40 points for radio, 30 for television and 10 for the press). The difference between state institutions and the media 'trust points' constitutes +50 points, which is the Comparative Media Trust Index (CMTI). The same model was used for the calculations for all countries surveyed in the Standard Eurobarometer 62 and $74 . .^{5}$

All ranking systems have shortcomings of their own, and the CMTI is not an exception. We should mention some weaknesses of the CMTI: the very data used for comparison could be seriously questioned; error limits are ignored; in diverse cultural environments the understanding of trust may have different meanings; and attempts to convert qualitative data into quantitative quotients should always be seriously questioned.

The initial analysis of the CMTI data revealed another weakness of the proposed comparison: countries with a high trust culture (for example the Netherlands) received a comparatively low CMTI (-30 in 2004 and +30 in 2010) and may therefore have been placed in the category of low trust societies. Standard Eurobarometer data showed that the Dutch have a high level of trust in most state institutions, but this trust is slightly lower than the trust in media. In order to overcome this shortcoming, we decided to take into consideration 'gross trust' as well. In our case 'gross trust' is calculated by summing up (positive

\footnotetext{
4 In 2004 (Standard Eurobarometer 62), in all European states, the police (except Cyprus) and the army (except Luxemburg) were among the three most trusted state institutions and were used for comparison. In these two exceptions, government and parliament were trusted more. Justice/national legal system was the third candidate in the 'most trusted trio'. Governments were trusted less and parliament had the worst results. In 2010 (Standard Eurobarometer 74), in all European states, the police were among the three most trusted state institutions and were used for comparison in all cases. The army was not included throughout Europe, except in the case of Sweden (the parliament is trusted more than the army). Justice/national legal system was displaced from the most trusted institutions trio in five cases. In Belgium, Luxemburg and Slovakia, the parliament is trusted more, and in Bulgaria and Macedonia, the government overtook justice.

5 If two institutions were trusted equally, we applied 5 points as well.
} 
and negative) trust in media and the three most trusted state institutions which were used for the calculation of the CMTI for each country. The transfer of the CMTI and 'gross trust' (which could be simply called S+M according to the CMTI calculation formula) into a system of coordinates whereby the CMTI is plotted on the $x$ axis and $S+M$ on the $y$ axis, helps us to identify different 'trust groups' throughout Europe. While comparing data from 2004 and 2010, we were therefore able to track certain changes and even notice some tendencies.

\section{Trust quarters and models}

The CMTI and its comparison with 'gross trust' was used for a pilot analysis in which we tried to compare trust in media and state institutions throughout Europe. The analysis was based on the data from the Eurobarometer: publicly accessible data from the 2004 and 2010 autumn waves of the Standard Eurobarometer $(62,74)$ were used. The choice of this time span for the analysis was principally determined by the availability of comparable data. Nevertheless, 2004 and 2010 are excellent years for the CMTI analysis. 2004 was the year of the first major EU eastward enlargement, and 2010 was the year of the 'mature' economic crisis, which undoubtedly had a profound impact on trust levels. A six-year time span allows an observation of the changes in the CMTI. The summarised results are presented in Figures 1 and 2, with more detailed data available in the annexe.

Formally, all of the analysed countries could be divided into four groups according to their place in the system of coordinates, with the CMTI and $\mathrm{S}_{+} \mathrm{M}$ proportion trend line used as a benchmark line instead of the $x$ axis, and $S+M$ as the $y$ axis. Countries in 'the positive gross trust' zone, which are above the trend line (this means people in these countries trust state and media more than the average of all of the analysed countries), could be divided into two sectors, with a negative CMTI on the left and a positive CMTI on the right. The same division could be applied to 'the negative gross trust' zone as well. An analysis of data from 2004 and 2010 allows us to divide all European countries into these four quarters, which - with some reservations - we identify as Transitional, Nordic, Post-communist and Mediterranean models. Segmentation lines between the quarters should not be understood as being very strict, and all four models should be characterised at least in brief.

(1) While comparing 2004 and 2010 data, we found only one 'permanent resident' of the first quarter: Belgium. In the countries attributed to this group, people's trust in state and media is higher than average. At the same time 
we could detect an inclination to trust media more than the state (negative CMTI). Such a position of 'media-orientated high trust' for Belgium could easily be explained by the country's deep cultural and linguistic division, which inevitably influences (dis)trust in the state and its institutions while preserving an overall high level of trust. We presume that a separate evaluation of the CMTI in Flanders and Wallonia (if we measure trust in local instead of central government) would provide very different results. This prompted us to name the first quarter 'the Transitional Model'. The CMTI measurement for Iceland in 2010 supported this decision. As a newcomer to the Standard Eurobarometer measurements, Iceland was positioned in the 'media-orientated high trust' quarter. The severe financial crisis and loss of trust in government had probably influenced the CMTI for Iceland; it would be quite natural to presume that in 2004, Iceland would have been in the 'state-orientated high trust' quarter together with its neighbours Denmark, Sweden and Finland.

Figure 1: Comparative Media Trust Index and 'gross trust' $(S+M)$, European countries in 2004. (Standard Eurobarometer 62 data)

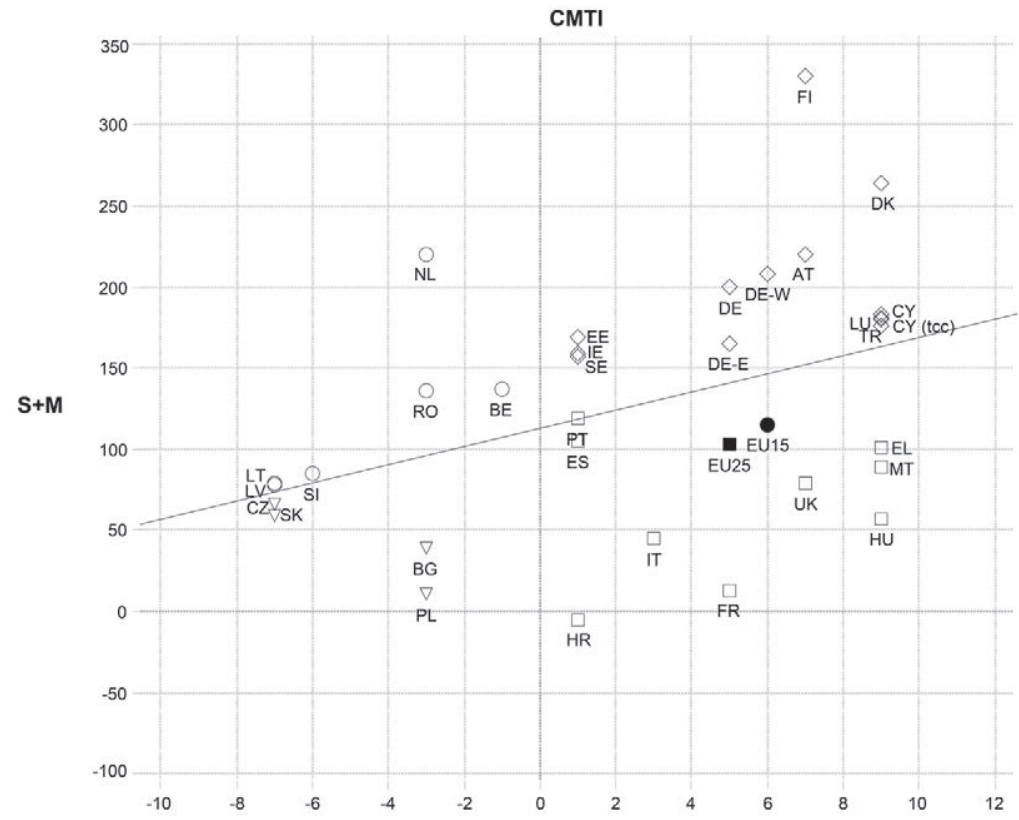

Country Groups

$\diamond \mathrm{EB} 62 \mathrm{AT}, \mathrm{EB} 62 \mathrm{CY}, \mathrm{EB} 62 \mathrm{CY}$ (tcc), EB62 DE, EB62 DE-E, EB62 DE-W, EB62 DK, EB62 EE, EB62 FI, EB62 IE, EB62 LU, EB62 SE, EB62 TR

EB62 BE, EB62 LT, EB62 LV, EB62 NL, EB62 RO, EB62 SI

$\nabla$ EB62 BG, EB62 CZ, EB62 PL, EB62 SK

$\square$ EB62 EL, EB62 ES, EB62 FR, EB62 HR, EB62 HU, EB62 IT, EB62 MT, EB62 PT, EB62 UK

- EB62 EU15

EB62 EU25 
Figure 2: Comparative Media Trust Index and 'gross trust' $(S+M)$, European countries in 2010. (Standard Eurobarometer 74 data)

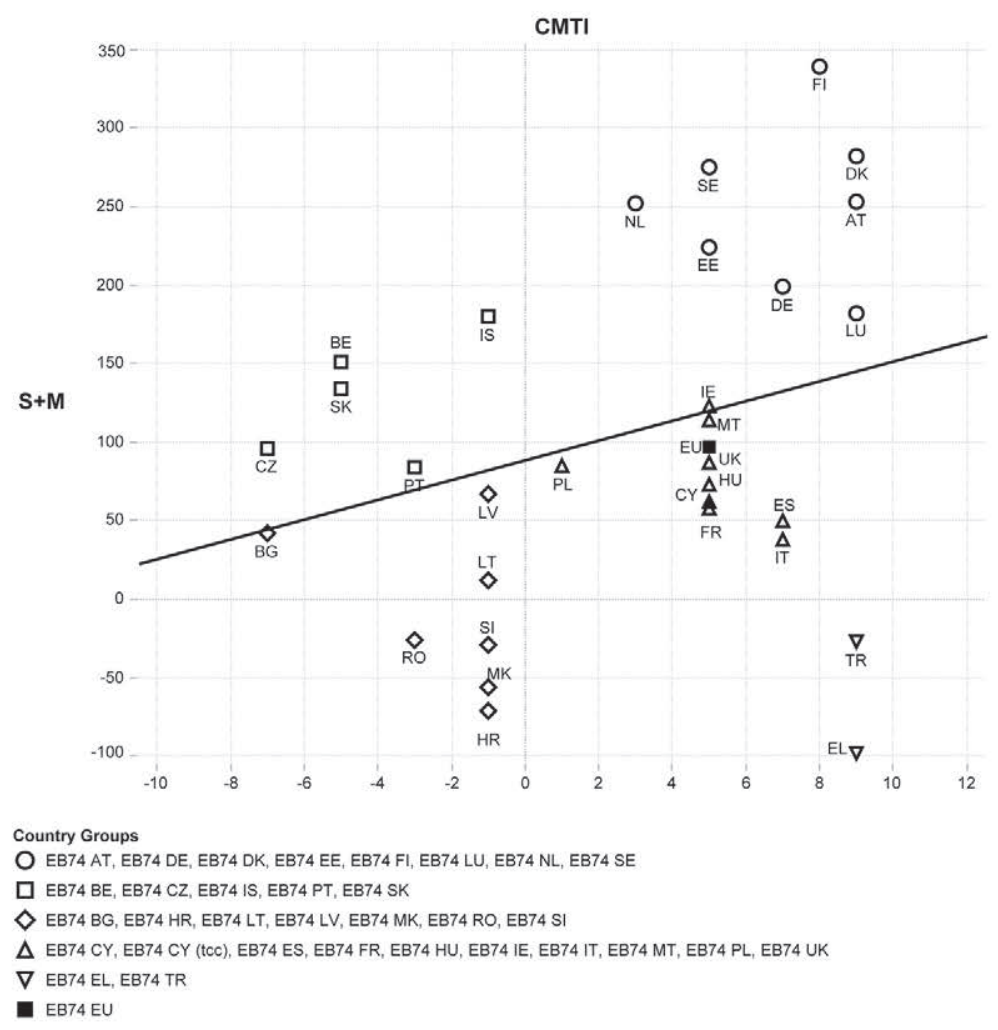

We can also detect a comparable move in the opposite direction from the 'media-orientated high trust' quarter towards the 'state-orientated high trust' quarter occupied by the Netherlands. In 2004, the Dutch style of trust was more comparable with that seen in Belgium, but in 2010, it had evolved towards a Nordic and German style. There may of course be more profound reasons for such a move, but let us mention that fieldwork for the EB74 was performed in November 2010, just a few weeks after the formation of the new Dutch government. The first months of new leadership are often accompanied by a surge in new public hopes. This may apply to the Dutch situation after the 2010 snap elections, with devastating results for the largest ruling party, the worrisome success of Geert Wilders' extreme right-wing party and the unprecedented minority government. 
(2) The second quarter of 'state-orientated high trust' countries permanently (according 2004 and 2010 data) includes the Nordic EU members (Denmark, Sweden and Finland) and the German-speaking countries of Austria, Germany and Luxembourg (which is partially German-speaking). In both measurements, Ireland was on the very edge of the 'state-orientated high trust' group. All of the members of the group are 'old and mature' democracies with the exception of Estonia. In this case, we should take into account the consistent Estonian orientation towards the Nordic dimension. The CMTI analysis indirectly confirms the success of such a policy and allows us to presume that the fact that Estonia pushes for distinction from other Baltic states could be more deep-rooted than generally presumed, as Latvia and Lithuania are nearly permanent members ${ }^{6}$ of the third quarter, which is characterised as 'media-orientated low trust'.

In 2004, the second quarter was much more 'crowded' than in 2010, but according to EB62, some countries (such as Portugal) were literally 'on the edge' of the quarter, while others (Cyprus and Turkey) were near the edge. During the financial crisis, Portugal switched to the Transitional Model, whereas Cyprus and Turkey could be identified as belonging to the Mediterranean Model in 2010. Let us point out that the core countries of the Nordic Model moved in the opposite direction during the financial crisis, when they became even more trusting and more state orientated.

Figure 3: Four models of trust throughout Europe.

\begin{tabular}{|c|c|}
\hline $\begin{array}{l}\text { TRANSITIONAL MODEL } \\
\text { MEDIA-ORIENTATED HIGH TRUST } \\
\text { (BE) }\end{array}$ & $\begin{array}{c}\text { NORDIC MODEL } \\
\text { STATE-ORIENTATED HIGH TRUST } \\
\text { (AT, DE, DK, EE, FI, IE, LU, SE) }\end{array}$ \\
\hline $\begin{array}{c}\text { POST-COMMUNIST MODEL } \\
\text { MEDIA-ORIENTATED LOW TRUST } \\
\text { (BG, LT, LV, SI) }\end{array}$ & $\begin{array}{c}\text { MEDITERRANEAN MODEL } \\
\text { STATE-ORIENTATED LOW TRUST } \\
\text { (EU, ES, FR, HU, IT, MT, UK) }\end{array}$ \\
\hline
\end{tabular}

(3) The 'state-orientated high trust' group comprises mature democracies with only one exception, whereas the 'media-orientated low trust' quarter is made up exclusively by 'new democracies' with fresh reminiscences of Sovietdominated communism. So its identification as a Post-communist Model ap-

\footnotetext{
${ }^{6}$ According to the 2004 Eurobarometer measurement, Latvia and Lithuania could be called 'the third quarter border countries. Together with Slovenia they were on the edge of the first quarter.
} 
pears quite natural. Permanent members of the group besides the previously mentioned two Baltic states include Slovenia and Bulgaria. In 2004, Romania was in the first quarter, but in 2010 moved well into the third. Czech Republic and Slovakia moved in the opposite direction during the same years, while Poland left the third quarter for the fourth (in fact, Poland changed places with Croatia).

(4) The fourth quarter is comprised of 'state-orientated low trust' countries, and includes all measurements of EU averages (EU15 and EU25 in 2004 and EU27 in 2010) and such individual countries as the Mediterranean states (Italy, France, Malta, Spain), the United Kingdom and Hungary. Besides these 'permanent' members of the group, the so-called Mediterranean Model should include Cyprus, Greece and Turkey, which were on the 'edge' of the 'state-orientated high trust' countries in 2004, but moved very clearly into the fourth quarter in 2010. It is evident that the United Kingdom and Hungary somehow dropped out of the geographical definition of the Mediterranean Model. There are no doubts that the United Kingdom had nourished a unique media consumption model, which could naturally lead to a distinctive mode of trust. Traditionally, the Anglo-Saxon world is associated with the Nordic or Germanic way of life. The CMTI analysis could lead to the revision of some stereotypes. But it is too early to draw any conclusions. Hungary is the only post-communist country which in both measurements found itself in the Mediterranean Model. Some explanations of the Hungarian case could be associated with the recent past: Goulash Communism (gulyáskommunizmus) helped Hungarians find a very special place in the former Warsaw Pact zone, which in its own term influenced Hungarian distinctiveness.

At this stage of research, it would probably be too early and too bold to draw any conclusions. The idea of four models of trust needs more comprehensive analysis, but we should note that the comparison of different models of trust could serve as a potential instrument for a deeper understanding of the society, state and media triangle. Comparing trust in media and state institutions has a potential to show the levels of democratisation of society: the difference between trust and doubt in democratically elected bodies and unelected commercial media enterprises indirectly shows peoples' satisfaction with the state of democracy and its perspectives. 


\section{Four trust models and three media systems}

In order to assess the 'four models of trust', we tried to compare them with already existing studies. From our point of view, the famous and influential research work Comparing Media Systems: Three Models of Media and Politics by Hallin and Mancini (2004) provides us with an excellent foundation. After a comprehensive comparative study of 18 western democracies, the authors identified three media systems: Mediterranean or polarised pluralist (France, Greece, Italy, Portugal, Spain); North/Central Europe or democratic corporatist (Austria, Belgium, Denmark, Finland, Germany, Netherlands, Norway, Sweden, Switzerland); and North Atlantic or liberal (United Kingdom, United States, Canada, Ireland). According to Hallin and Mancini, "[t]he discussions of the three media system models are essentially organised around the four variables [...]: the development of media markets and particularly of the mass circulation press, political parallelism, journalistic professionalism, and the role of the state [in media system]" (Hallin \& Mancini, 2004: 87). Hallin and Mancini were analysing 'mature' western democracies, while such newborn (or reborn) democracies as central and eastern European countries were out of their sphere of interest; in our measurements we do not examine such non-EU countries as Norway, Switzerland, United States or Canada. Nevertheless, comparisons have various similarities and the potential to strengthen both argumentations.

Nearly all countries (except the Netherlands in 2004, Portugal in 2010 and Belgium in both measurements) analysed by Hallin and Mancini belong to the two models of trust which we identify as 'state orientated'. This allows us to presume that the positive or negative CMTI (i.e. the difference between trust in state institutions and media) could be one of the important signs of a 'mature democracy'. The abovementioned 'unusual' position of Belgium, the 'migration' of the Netherlands and Portugal, as well as the position of Iceland support the opinion that a 'media-orientated high trust' model could be referred to as 'transitional', as an appearance in this quarter of the CMTI could be interpreted as a sign of crisis for a mature democracy or a transitional point for a new one. All of the countries which were permanently - or at least in one of the measurements - identified as 'media-orientated low trust' were out of the scope of research of Hallin and Mancini (2004). Such a situation supports our idea that the 'media-orientated low trust' style of trust is characteristic of post-communist societies. In the creation of democratic institutions, joining the European Union is probably a quicker process than the transition from one model of trust to another. The media system which Hallin and Mancini (2004) referred to as 
"Mediterranean or polarised pluralist" very much fits our 'state-orientated low trust' model, in the same was as "North/Central Europe or democratic corporatist" corresponds to the 'state-orientated high trust' model. Countries referred to by Hallin and Mancini (2004) as "North Atlantic or liberal" are somewhere in between. Such a positioning of the North Atlantic or liberal media system comes as a surprise. We lack comparable data for a more precise description of the North Atlantic or liberal media system, as the United States and Canada are beyond the limits of our study. But data from the United Kingdom and Ireland predict that North Atlantic or liberal media system countries remind us more of the Mediterranean or polarised pluralist than the North/Central Europe or democratic corporatist media system. But we should take into account the unique British model of trust. The United Kingdom has the lowest level of trust in the press (minus 68 and minus 61 in 2004 and 2010 respectively), which, together with a large circulation of tabloid newspapers, allows us to speak of some sort of communicative game, whereby press customers like the product and use it, but do not trust it. Recent developments in the United Kingdom confirm that such a situation cannot last for long and its impact on society is contradictive. As Steven Barnett critically notes, “[j] ournalism’s decline cannot, therefore, be seen in isolation from a more widespread phenomenon of declining faith. [...] [T] he scale and speed of the decline in trust is a serious issue" (Barnett, 2008: 10).

These efforts to look for links between three media systems and four trust models lead to the idea that the evolution of trust in democratic societies may develop in slightly different forms and that media systems may be influenced by this evolution. At this point in our research it is difficult to conclude with certainty that either the established media system determines the model of trust or the model of trust helps build the system. Here we would like to mention the following remark by Kathleen Jamieson and Joseph Cappella: "We do know that people do not trust the mainstream media and that those who trust it least are also those most interested in public policy" (Jamieson \& Cappella, 1997: 213).

Trust models dominating different media systems allow us to look back at delicate problems in civic society, its forms and its maturity. In this context, we should make a brief reference to Jürgen Habermas and his ideas about the public sphere and civil society, which "came into existence as the corollary of a depersonalised state authority" (Habermas, 2008: 19). Habermas' ideas about the public sphere as the space between civil society and the state could be useful for 
future research. Here we should also mention John Nerone's view that [public] "space allows citizens to address the state but demands that they leave their individual interests behind when they do so" (Nerone, 1995: 154). The demand to surrender egoistic interests applies to media organisations as well. The maturity of democracy or the public sphere is a comparative category which could be understood in a different manner. But at this point we do not doubt that one of the most important questions may be the congruence between media system and model of trust.

\section{Concluding remarks}

Trust is always a risk. One of the principal questions which is raised in every society is how this risk should be divided and managed. In this article our attention was focused on the primary sources of societal trust and the division of this trust between media and state institutions. It is hard to imagine democracy without the fierce competition of ideas, and the division of this battlefield always looks a bit artificial. Both sides (media and state or political institutions) in this fight for democracy deserve respect and should be nourished. In this case, the promotion of competition while at the same time maintaining the balance helps create a foundation for societal peace.

The state has administrative restrictive powers and always appears to be more powerful. This image is successfully cultivated by the media and is indirectly supported by politicians who often feel a temptation to use their authority. On the other hand, the media are not always on the weak side in the competition with politics. The media business is huge and influential, and has its own interests. Risks of media-democracy and its special type of TV-democracy are not imaginable. And 'infotainment' is only a side effect of this disease. Other symptoms should include "a corrosive individualism, a psychological impulse, negative, anti-institutional, sloganeering campaigns, and disjunctures between the promise and performance of leaders [which] may have contributed to the escalation in public cynicism about institutions" (Jamieson \& Cappella, 1997: 29).

The first insights gained through the CMTI regarding the balance between trust in media and state institutions throughout Europe could lead to rather optimistic conclusions. In experienced democracies, primary trust lies in democratically elected state institutions, and trust in media could be characterised as secondary. Countries with fresh reminiscences of a totalitarian past still live in a transitional period where the understanding of roles of the state and the media 
is influenced by difficult memories of distrust. Perhaps we can imagine a 'spiral of trust' which differs from a well-known 'spiral of silence'. 'The spiral of trust' is in permanent movement: it shrinks and expands. The distribution of trust is an everlasting search for balance. Throughout Europe, different phases of this process can now be seen. 


\section{References}

Barnett, S. (2008). On the Road to Self-destruction. British Journalism Review, 19(2), 5-13.

Coleman, S. (2012). Believing the News: From Sinking Trust to Atrophied Efficacy. European Journal of Communication, 27(1), 35-45.

Fukuyama, F. (1996). Trust: The Social Virtues and the Creation of Prosperity. New York: Free Press Paperbacks, Simon and Schuster.

Habermas, J. (2008). The Structural Transformation of the Public Sphere. Cambridge: Polity Press.

Hallin, D. C. \& Mancini, P. B. (2004). Comparing Media Systems: Three Models of Media and Politics. Cambridge, New York, Melbourne: Cambridge University Press.

Jamieson, K. H. \& Cappella, J. N. (1997). Spiral of Cynicism: The Press and the Public Good. Cary: Oxford University Press.

Kohring, M. \& Matthes, J. (2007). Trust in News Media: Development and Validation of a Multidimensional Scale. Communication Research, 34(2), 231-252.

Luhmann, N. (1979). Trust and Power. New York: John Wiley.

Misztal, B. A. (1996). Trust in Modern Society: The Search for the Bases of Social Order. Cambridge: Polity Press.

Nerone, J. C. (ed.) (1995). Last Rights: Revisiting Four Theories of the Press, Chicago: University of Illinois Press.

Newton, K. (2007). Social and Political Trust. In Dalton, R. J. \& Klingemann, H. D. (ed.), The Oxford Handbook of Political Behavior. New York: Oxford University Press, pp. $342-361$.

Seligman, A. B. (1997). The Problem of Trust. Princeton: Princeton University Press.

Standard Eurobarometer 62 (2004). Tables of results. Accessed 12.01.2012. URL: http://ec.europa.eu/public_opinion/archives/eb/eb62/eb62_en.htm.

Standard Eurobarometer 74 (2010). Tables of results. Accessed 12.01.2012.

URL: http://ec.europa.eu/public_opinion/archives/eb/eb74/eb74_en.htm. 


\begin{tabular}{|c|c|c|c|c|c|c|c|c|c|c|c|c|c|c|c|c|}
\hline$\sum_{+}$ & $\cong$ & 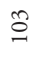 & $\widehat{\infty}$ & के & ৫ & ث্ণ & ஓे & $\stackrel{\infty}{\stackrel{\sim}{े}}$ & $\stackrel{n}{\varrho}$ & $\stackrel{\theta}{\circ}$ & $\stackrel{\approx}{\sim}$ & 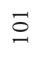 & $\tilde{\varrho}$ & 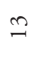 & f & $\stackrel{\infty}{-}$ \\
\hline E & 8 & in & $\stackrel{0}{1}$ & ధి & $\stackrel{R}{i}$ & ฉ & in & 8 & in & 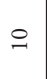 & $\stackrel{ }{1}$ & \& & 으 & in & m & ฉ \\
\hline 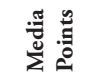 & $\Re$ & $\infty$ & $\stackrel{\circ}{\exists}$ & $\stackrel{\text { త్ }}{ }$ & $\stackrel{\circ}{ \pm}$ & 8 & $\infty$ & $\Re$ & $\triangleright$ & 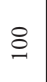 &  & 8 & 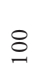 & $\triangleright$ & ฉ & 8 \\
\hline 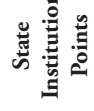 & $\tilde{n}$ & $\stackrel{m}{\rightarrow}$ & 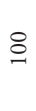 & ฉ & $尺$ & $\stackrel{̊}{n}$ &  & $\stackrel{n}{n}$ & 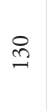 & 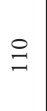 & $\supseteqq$ & $\stackrel{\Re}{n}$ & $\supseteqq$ & 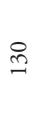 & $\stackrel{\overbrace{}}{\beth}$ & $\stackrel{\cap}{n}$ \\
\hline 㟒 & $\sum_{\substack{n \\
\sum}}^{\infty}$ & $\sum_{\infty}^{\infty}$ & $\begin{array}{l}\sum_{\bar{n}}^{n} \\
\sum_{n}^{n} \\
\sum_{n}^{n}\end{array}$ & $\frac{\sum_{n}^{\infty}}{\sum_{n}^{n}}$ & $\sum_{\sum}^{\infty}$ & $\sum_{\substack{\infty \\
心}}^{\sum_{\infty}}$ & $\sum_{\tilde{\infty}}^{\sum_{\infty}^{\infty}}$ & $\sum_{\substack{n \\
\infty}}^{\sum_{n}^{\infty}}$ & $\sum_{\infty}^{\infty}$ & 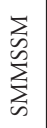 & $\sum_{\substack{n \\
n}}^{\infty}$ & $\sum_{\tilde{\omega}}^{\sum_{n}}$ & $\sum_{\substack{\infty \\
\sum}}^{\sum_{n}^{\infty}}$ & $\sum_{\infty}^{\sum_{\infty}^{\infty}}$ & $\sum_{\infty}^{\infty}$ & 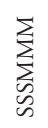 \\
\hline
\end{tabular}

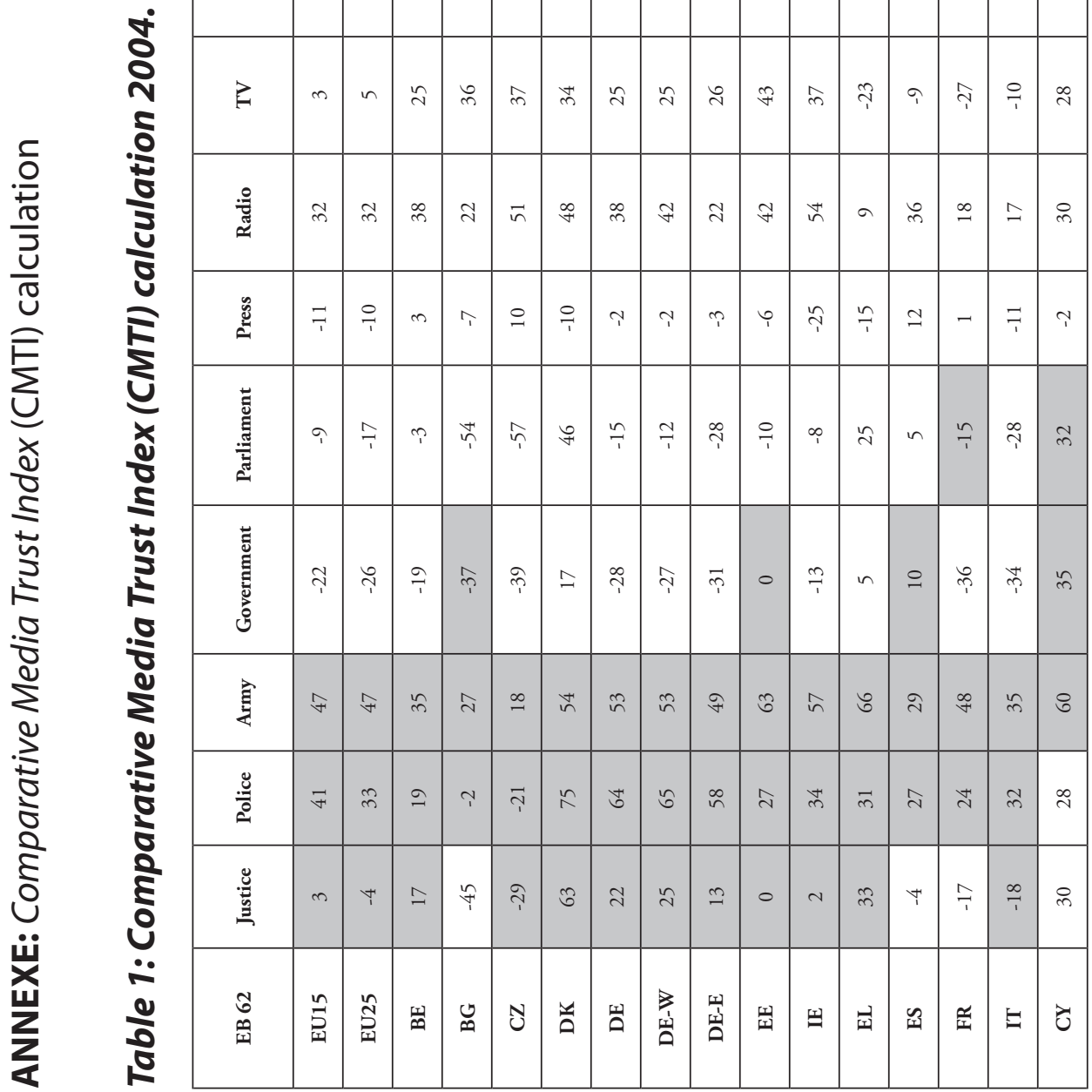




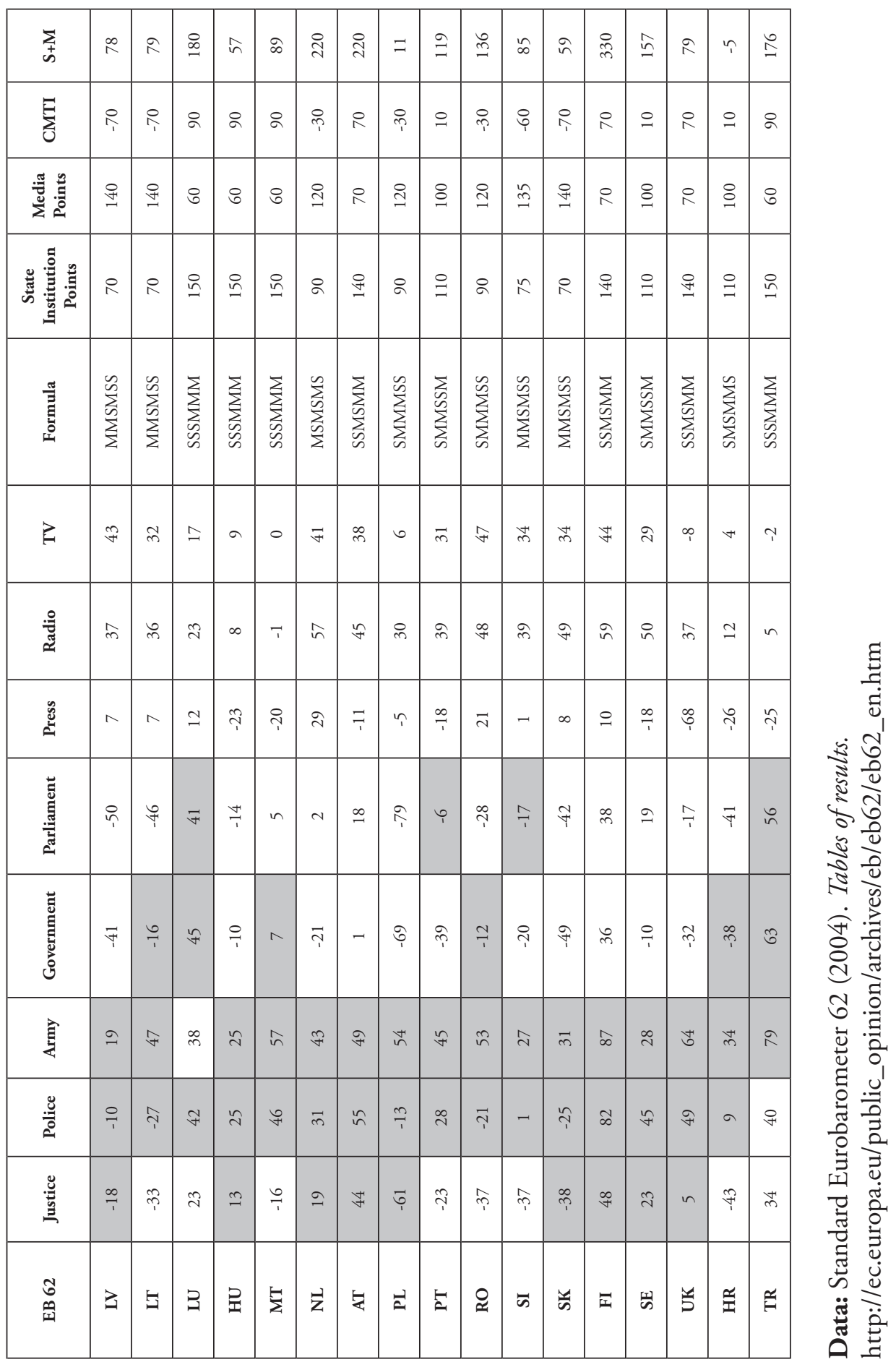




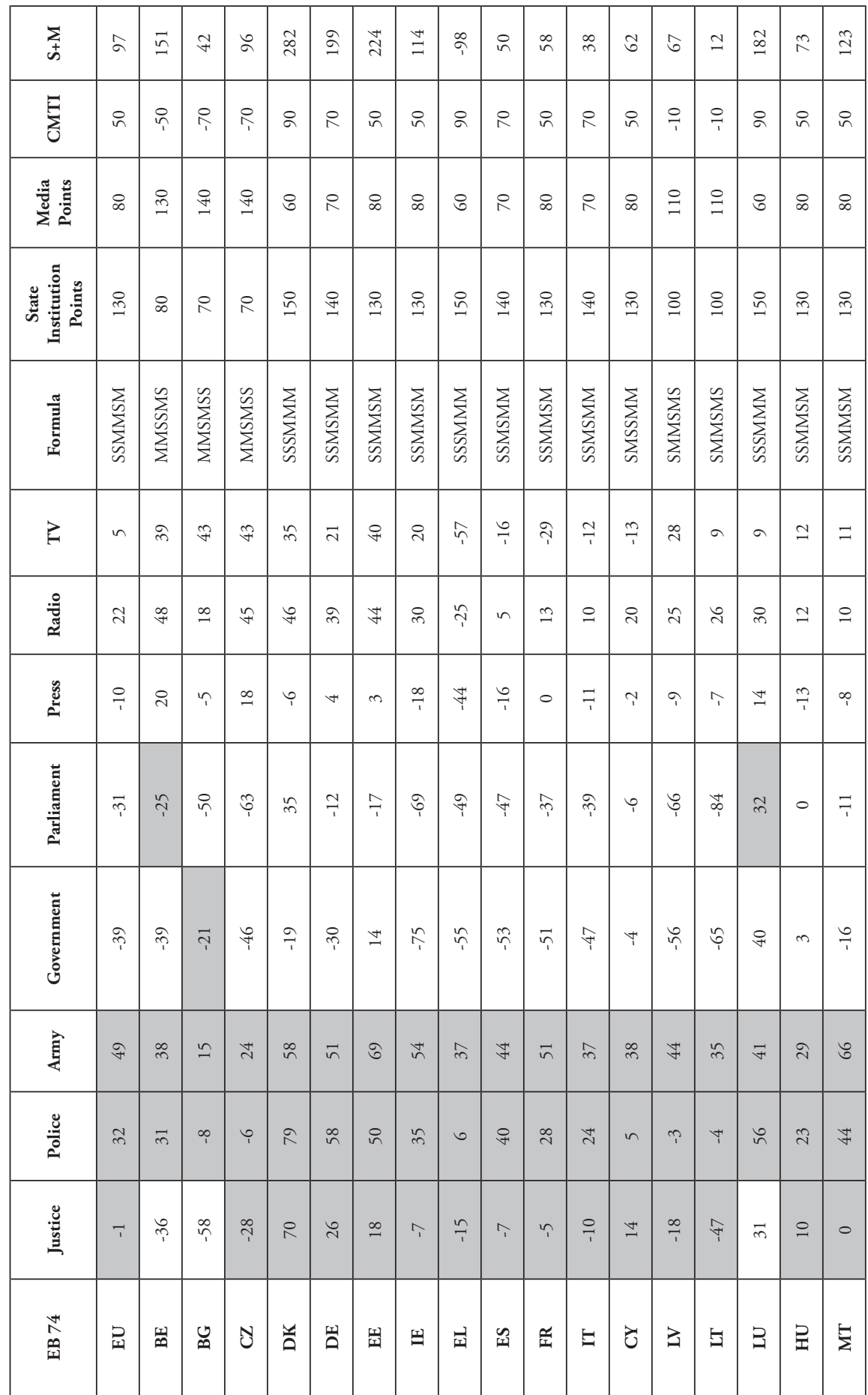




\begin{tabular}{|c|c|c|c|c|c|c|c|c|c|c|c|c|c|c|}
\hline$\sum_{j}$ & $\widetilde{\approx}$ & $\approx$ & $\approx$ & $\underset{\infty}{+}$ & $\stackrel{\sim}{i}$ & ते & $\ddot{m}$ & $\widehat{\approx}$ & $\stackrel{\varkappa}{\bumpeq}$ & $\widehat{\infty}$ & $\vec{i}$ & $\widehat{\widehat{\imath}}$ & $\stackrel{\sim}{n}$ & $\stackrel{\infty}{\rightarrow}$ \\
\hline$\sum_{j}^{E}$ & లి & ฉ & 으 & क्? & ;) & $\stackrel{\circ}{\div}$ & $\stackrel{i}{n}$ & $\infty$ & in & $\stackrel{\circ}{n}$ & $\stackrel{ }{\div}$ & ฉ & $\stackrel{\circ}{\div}$ & $\stackrel{\circ}{7}$ \\
\hline 旁 & ฉ & 8 & 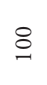 & త్ & $\stackrel{\text { తి }}{1}$ & $\stackrel{\varrho}{\exists}$ & 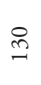 & $\tilde{b}$ & $\infty$ & $\infty$ & $\stackrel{\varrho}{\exists}$ & 8 & $\stackrel{\bigcirc}{\exists}$ & $\stackrel{\circ}{\exists}$ \\
\hline 总善总 & తి & $\stackrel{n}{n}$ & $\stackrel{\bigcirc}{\exists}$ & ฉ & ฉ & $\nsubseteq$ & 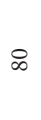 & $\stackrel{\varkappa}{ \pm}$ & 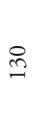 & $\stackrel{-}{2}$ & 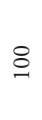 & 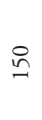 & $\stackrel{-}{\circ}$ & $\nsubseteq$ \\
\hline 童 & $\sum_{\substack{\infty \\
\infty}}^{\infty}$ & $\sum_{\infty}^{\infty}$ & $\sum_{n}^{\infty}$ & $\sum_{\sum}^{\infty}$ & $\sum_{\infty}^{\infty}$ & $\sum_{\infty}^{\infty}$ & $\sum_{\sum}^{\infty}$ & $\sum_{\infty}^{\infty}$ & $\sum_{\substack{\infty \\
\infty}}^{\infty}$ & $\sum_{\infty}^{\infty}$ & $\sum_{\infty}^{\infty}$ & $\sum_{\infty}^{\infty}$ & $\sum_{n}^{\infty}$ & $\sum_{\infty}^{\infty}$ \\
\hline$\geq$ & శె & $\stackrel{m}{m}$ & $a$ & $\tilde{m}$ & $=$ & 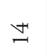 & $\hat{m}$ & $\mathscr{*}$ & 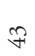 & 0 & 0 & $\stackrel{\infty}{\uparrow}$ & $\stackrel{\circ}{\circ}$ & $\hat{f}$ \\
\hline 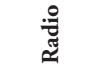 & $\hat{n}$ & $\vec{\forall}$ & $\stackrel{\sim}{\sim}$ & $\stackrel{\sim}{\sim}$ & $\stackrel{\circ}{-}$ & $\mathscr{\sim}$ & $\curvearrowleft$ & $\stackrel{n}{n}$ & 8 & 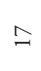 & $m$ & $\hat{\imath}$ & $\underset{T}{T}$ & $\stackrel{\imath}{n}$ \\
\hline 总 & $\approx$ & $\vec{\sim}$ & $\uparrow$ & $\stackrel{\circ}{\sim}$ & $\boldsymbol{i}$ & $\stackrel{\vartheta}{\overrightarrow{1}}$ & ㄱ. & $\stackrel{\sim}{\sim}$ & 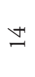 & $\vec{\varphi}$ & $\stackrel{\sim}{\vartheta}$ & $\stackrel{\circ}{+}$ & ণิ & $\uparrow$ \\
\hline 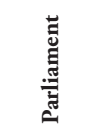 & $\cong$ & $v^{*}$ & $\underset{7}{Y}$ & $\vec{F}$ & $\stackrel{\gtrless}{\uparrow}$ & ?: & สี & $\stackrel{ }{ }$ & ff & $\hat{\imath}$ & $\stackrel{\infty}{\uparrow}$ & 0 & in & F \\
\hline 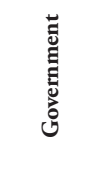 & 0 & $T$ & $\stackrel{\oplus}{1}$ & $\stackrel{\infty}{\imath}$ & $\vec{i}$ & Ț & $\stackrel{\underset{\imath}{*}}{\sim}$ & W & $\stackrel{\infty}{\sim}$ & 아 & $\stackrel{\infty}{\uparrow}$ & P & $\bar{F}$ & $\bar{F}$ \\
\hline 蚉 & in & $\approx$ & $i n$ & हి & $\stackrel{\sim}{\sim}$ & 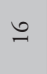 & $\stackrel{\infty}{+}$ & $\varpi_{\infty}^{+1}$ & $\approx$ & $\Re$ & $\stackrel{\infty}{\sim}$ & $\stackrel{\leftrightarrow}{+}$ & $\stackrel{\sim}{\sim}$ & क् \\
\hline$\stackrel{\dddot{0}}{\circ}$ & $\stackrel{\infty}{+}$ & $\stackrel{\infty}{n}$ & 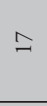 & 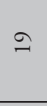 & $\vec{\Upsilon}$ & $\neg$ & 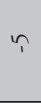 & $\infty$ & $\approx$ & $\approx$ & $\overline{7}$ & $\tilde{\sim}$ & $\stackrel{0}{7}$ & $\ddot{\infty}$ \\
\hline 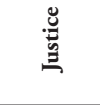 & $\stackrel{m}{m}$ & $\approx$ & $\frac{n}{1}$ & Fi & $\tilde{\psi}$ & $\tilde{\kappa}$ & 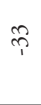 & $\stackrel{n}{n}$ & $\stackrel{\infty}{+\infty}$ & in & $\stackrel{\sim}{\imath}$ & $\stackrel{\circ}{=}$ & $\stackrel{\infty}{+}$ & $\stackrel{\sim}{i}$ \\
\hline $\begin{array}{l}\hat{N} \\
0 \\
0\end{array}$ & $\vec{z}$ & 穵 & $\vec{a}$ & $\Sigma$ & $\stackrel{2}{\mathscr{A}}$ & $\bar{\omega}$ & ๘ & $\vec{I}$ & 대 & 光 & 舀 & $\stackrel{\text { 光 }}{ }$ & $\frac{u}{\Sigma}$ & $\Omega$ \\
\hline
\end{tabular}

